\title{
Accelerated chondrogenesis in nanofiber polymeric scaffolds embedded with BMP-2 genetically engineered chondrocytes
}

\author{
Robert T. Gorsline ${ }^{1,2}$, Prasam Tangkawattana ${ }^{3}$, John J. Lannutti ${ }^{4}$, Mamoru Yamaguchi ${ }^{3}$, Christopher \\ C. Kaeding ${ }^{2}$, Alicia L. Bertone ${ }^{1,2}$ \\ ${ }^{1}$ Comparative Orthopaedic Research Laboratories, The Ohio State University, Columbus, USA; \\ ${ }^{2}$ Department of Orthopaedics, College of Medicine, The Ohio State University, Columbus, USA; \\ ${ }^{3}$ Department of Veterinary Biosciences, College of Veterinary Medicine, The Ohio State University, Columbus, USA; \\ ${ }^{4}$ Department of Biomedical Engineering, College of Engineering, The Ohio State University, Columbus, USA. \\ Email: bertone.1@osu.edu
}

Received 28 June 2010; revised 19 July 2010; accepted 20 July 2010.

\section{ABSTRACT}

This study evaluated chondrogenesis within a nanofiber polymeric scaffold seeded with isolated untreated chondrocytes, isolated chondrocytes genetically engineered with adenoviral (Ad) bone morphogenetic protein (BMP)-2, or isolated chondrocytes genetically engineered with green fluorescent protein (Ad-GFP). Electrospun polycaprolactone scaffolds (150-200 $\mu \mathrm{m}$ thickness, $700 \mu \mathrm{m}$ fiber diameter, $30 \mu \mathrm{m}$ pore size) were optimally seeded with 1 x 107 isolated chondrocytes by using a $20 \%$ serum gradient culture system. Chondrocyte- scaffold constructs (untreated, Ad-BMP-2 and Ad-GFP) were generated from 5 adult horses, cultured in triplicate for 7 or 14 days, and quantitatively analyzed for cell proliferation (DNA content; Hoechst assay), viability, morphology (confocal microscopy), matrix production (proteoglycan content; DMMB assay), and mRNA expression of collagen $I$, collagen II, and aggrecan. Chondrocytes transduced with Ad-BMP-2 demonstrated greater cell numbers and significantly greater expression of chondrogenic markers including aggrecan, collagen II, and proteoglycan through 14 days of culture as compared to untransduced or Ad-GFP controls. This study demonstrated that chondrocytes can be driven to seed a polycaprolactone nanofiber scaffold by serum gradient and a polycaprolactone nanofiber scaffold containing Ad-BMP2 transduced chondrocytes resulted in greater and accelerated chondrogenesis than controls. This cell engineered construct has potential use in onestep cartilage repair in vivo.

Keywords: Nanofiber; Scaffold; Chondrogenesis; BMP- 2; Adenovirus

\section{INTRODUCTION}

Articular cartilage defects heal poorly and combinations of progenitor chondrocytes, bioactive factors, and matrices are being applied as focal synthetic devices [1-3] Synthetic biodegradable polymers have served as scaffolds for articular cartilage tissue engineering. Studies have demonstrated that properties such as pore size, material composition, and diameter of the fibers are important for cell proliferation, adhesion, migration and maintenance of a chondrogenic phenotype of seeded cells [4-12]. Successful biodegradable polymeric scaffolds permissive to cell and tissue in-growth have been studied both in vitro and in vivo, including for chondrocytes[4,6-13]. Properties of successful scaffolds include interconnected pores permissive to cell adhesion, proliferation and migration, and fluid transport as well as biocompatibility. Scaffolds have been created from bioactive materials such as plasma, starch, collagen, hydrogel, hydroxyapatite, alginate, and periosteum [9,11,13-15] as well as the synthetic materials such as porous poly (l-lactic acid) [5,8,16], poly (glycerol sebacate) (PGS)[6], poly (1,8 octanediol- co-citrate) (POC) [6], poly (ethylene glycol)-terephtha- late/poly (butylene terephthalate (PEGT/PBT) [17] poly- caprolactone (PCL) [4-7,10,12,17-23] and poly (gamma- glutamic acid)-graft-chondroitin sulfate/PCL composites [24], polydioxone [25] and other PCL composites[8,13]

Recent publications support the use of a nanoscale fiber size and PCL material for tissue engineering of chondrocytes [4-6,9-10,12,21,23]. Use of a fiber material in a mesh pattern has been reported for chondrocytes and the optimum fiber material will consider fiber size and topography. Nanofiber technology and its influence on cell behavior is advancing the science of tissue engineering by providing a fiber on the scale of biologic fibers [1820,23]. It is proposed that fibers which closely mimic 
normal extra-cellular matrix or basement membrane structure will show improved cytocompatability. Typically, naturally occurring extra-cellular matrices and basement membranes are composed of proteins including fibronectin, collagen, hyaluronic acid, chondroitin sulfate, dermatan sulfate and proteoglycans. These proteins are fibrous and are on a nanofiber scale in size. PCL fibers in the 30-1500 nm diameter range have been demonstrated to have optimal structural integrity and, particularly under dynamic loading, supported a desirable cellular response in culture, including chondrocyte proliferation and matrix production [23]. Electrospinning is a well-established process that can produce a random meshwork of nanofibers, including PCL, with appropriate pore size to support cellular infiltration of the scaffold, including chondrocytes[4-5,9-10,12,23-24], stem cells[21,22,26], glioma cells[27], and endothelial cells[28].

Cell-based therapy in conjunction with scaffolds for tissue engineering of cartilage is supported in vitro [3,6, $8,10-12,23,24,26]$ and in vivo $[7,14,17,21-22,25]$ and is rapidly advancing toward clinical application [1-4]. [1-4] Typically the cell source for cartilage engineering is chondrocytes [3,6-12,14,21,23-25] or mesenchymal stem cells. [17,21-22,26,29-30] Specifically for articular cartilage repair, animal studies support the use of biodegradable scaffolds seeded with morcelized cartilage [25], chondrocytes[7,14,21] or direct injection of mesenchymal stem cells.[31] Supplementation with growth factors, such as transforming growth factor-beta 3 , a known regulator of cell growth and differentiation, could enhance chondrocyte density and integration [11]. Growth factor members of the TGF beta superfamily, such as the BMPs, are particularly beneficial in promoting chondrogenesis of mesenchymal stem cells [29-34] and can support cartilage matrix production $[35,36]$. Specifically, bone morphogenetic protein (BMP)-2 can regulate chondrocyte differentiation in progenitor cells[34], enhance bone formation through the endochondral ossification pathway[31,37], and can increase chondrocyte extracellular matrix production in vitro [35-36]. Mesenchymal stem cells genetically engineered to produce BMP-2 can enhance articular cartilage repair during articular fracture repair in vivo [31]. Our study focuses on the ability of the BMP-2 gene to support phenotype, proliferation, and matrix production of chondrocytes suspended in a biodegradable nanofiber PCL scaffold. We investigated whether BMP2 could successfully promote chondrogenesis in this 3dimensional scaffold for potential use in articular cartilage tissue engineering.

\section{METHODS}

\subsection{Study Design}

Chondrocytes were isolated and expanded in primary mo- nolayer culture. Chondrocytes were seeded onto the surface of three dimensional polycaprolactone nanofiber scaffolds and evaluated for scaffold penetration by histology cryosection and morphology by confocal microscopy under conditions of fetal bovine serum gradient (10 or 30\%), cell seeding density $\left(5.0 \times 10^{5} / \mathrm{ml}, 1.0 \times 10^{6} \mathrm{ml}\right.$, or $5.0 \times$ $10^{6} \mathrm{ml}$ ) and duration of cell growth (day 2,7, or 14). The best condition was selected and chondrocytes from 5 horses were seeded onto similar scaffolds, in duplicate, and were evaluated at two time points (day 7 or 14) for three cell preparations; isolated cells (untreated control), isolated cells transduced with Ad-GFP (vector control), and isolated cells transduced with Ad human (h) BMP-2 (experimental gene). Chondrocyte transduction and BMP-2 production were confirmed. Outcome assessments were cell proliferation, cell morphology, cell viability, BMP-2 production, extracellular proteoglycan matrix production, and chondrocyte gene expression of Type I and Type II collagen as well as aggrecan.

\subsection{Generation of Adenoviral Vector Constructs}

Recombinant adenoviral vector containing these 1547 base-pairs of human BMP-2 under the cytomegalovirus promoter were propagated [31]. Expression of transgene was verified in cell culture.

\subsection{Chondrocyte Preparation}

Chondrocytes from 5 adult horses [5-9 years] were harvested aseptically from articular cartilage of the femoropatellar joint and isolated by collagenase digestion. Chondrocytes were expanded in monolayer in Dulbecco's Modified Eagle Medium (DMEM; Gibco, Sigma-Aldrich, St. Louis, MO) supplemented with sodium penicillin at a concentration of $50 \mathrm{units} / \mathrm{ml}$, streptomycin at a concentration of 100 units $/ \mathrm{ml}$, and L-glutamine at a concentration of $29.2 \mathrm{mg} / \mathrm{ml}$ (supplemented DMEM) with 10\% fetal bovine serum (FBS). At 75\% confluence, cells were lifted, counted and pooled in equal concentrations and cultured in monolayer in flasks. Chondrocyte monolayer flasks had Ad vector transduction with Ad-GFP or AdBMP-2 performed at a multiplicity of infection (moi) of 17:1 (Adeno- $\mathrm{X}^{\mathrm{TM}}$ Rapid Titer Kit, BD Biosciences Clontech, Palo Alto, CA) at $37^{\circ} \mathrm{C}$ for a transduction time of $2 \mathrm{~h}$, washed and allowed to incubate overnight to achieve expression of transgene product. Transduction efficiency was determined by calculating the percent of cells fluorescing [525 nm wavelength] per microscopic field (200X) in the monolayer chondrocytes treated with AdGFP. Chondrocytes were harvested and allocated to PCL culture systems.

\subsection{Polycaprolactone Scaffolds}

Nanofibrous [ 700 nm diameter] PCL [MW 40,000, 
Sigma Aldrich, St. Louis, MO] matrices were created through an electrospinning process[18-22] to form 150$200 \mu \mathrm{m}$ thick 3 dimensional sheets containing $~ 88 \%$ porosity and an average pore size of $30 \mu \mathrm{m}$.[18] Sheets were cut into $25 \mathrm{~mm}$ diameter discs using a $25 \mathrm{~mm}$ circular leather punch and sterilized by ethanol treatment.

\subsection{Chondrocyte Culture on PCL Matrices}

The $25 \mathrm{~mm}$ diameter sterile 3D nano-fibrous PCL matrices were placed into Corning Costar Snapwell $12 \mathrm{~mm}$ inserts $^{\mathrm{TM}}$ [Corning Inc., Corning, NY] designed to fit into standard 6-well culture plates. Chondrocytes were seeded onto the PCL scaffolds by placing cells in supplemented DMEM into the Snapwell ${ }^{\circledR}$ inserts. Inserts were placed into standard 6-well culture plates containing supplemented DMEM with the assigned concentration of FBS to create a gradient of FBS across the scaffold construct.

\subsection{Preliminary Study}

Isolated chondrocytes were cultured on PCL matrices in triplicate for 18 different conditions representing 3 cell seeding densities of $5.0 \times 10^{5} / \mathrm{ml}, 1.0 \times 10^{6} / \mathrm{ml}$, or $5.0 \times$ $10 \% \mathrm{ml}, 2$ serum gradients of $10 \%$ or $30 \%$, and duration of culture of 2, 7 and 14 days. PCL/ cell matrices were embedded in OCT medium, snap frozen in liquid nitrogen, cryosectioned (10 microns), and stained with toluidine blue for microscopy or fixed for surface scanning electron microscopy (SEM) to assess fiber pattern and cell distribution. The cell seeding density and serum gradient that supported the greatest number and depth of penetration of chondrocytes in the PCL matrix was selected for use in subsequent experiments.

\subsection{Chondrogenesis of Genetically Engineered PCL/ Cell Matrices}

Using the best seeding conditions, isolated chondrocytes from 5 horses were cultured on PCL matrices in 12 replicates each of untreated, transduced with Ad-GFP, or transduced with Ad-hBMP-2 for 14 days. Media were changed on days 2,7 , and 14 and stored at $-80^{\circ} \mathrm{C}$. Constructs from at least 2 replicates from each horse from each treatment (untreated, Ad-GFP-treated and Ad-BMP-2-treated) cultured for 7 or 14 days were quantitatively evaluated for each parameter of cell proliferation (DNA [ $\mu \mathrm{g} / \mathrm{ml}]$; Hoechst assay), \% viability (live/ dead stain) and morphology (confocal microscopy), matrix proteoglycan expression (ng/ml; DMMB assay) and gene expression (mRNA quantitative RT-PCR) of aggrecan (ddCT), collagen 1 (ddCT) and collagen II (ddCT) using equine specific primers and probes. Aggrecan and collagen gene expression intensity was expressed as a ration to 18sRNA and between Ad-BMP-2 treated chondrocytes to untreated and Ad-GFP controls (ddCT). BMP-2 protein concentration (ng/ml; ELISA) in the media and chondrocyte GFP expression intensity were compared among untreated, Ad-GFP-treated and Ad-BMP-2-treated PCL/ cell matrices.

\subsection{Transgene and Protein Expression}

GFP fluorescence was quantified using an in vivo imaging system (IVIS ${ }^{\circledR}$, Xenogen Corporation, Alameda, CA) at day 2 post- transduction. GFP production was quantified as flux (photons of light produced per second per square centimeter per steradian, photons $/ \mathrm{s} / \mathrm{cm}^{2} / \mathrm{sr}$ ).[31]

Aliquots of media from PCL/ cell matrix culture systems were frozen at $-80^{\circ} \mathrm{C}$ on days 2,7 , and 14 . Production of hBMP-2 was quantified using enzyme-linked immunosobent assays (ELISAs) for recombinant human (rh) BMP-2 (Quantikine ${ }^{\circledR}$, R \& D Systems, Minneapolis, $\mathrm{MN}$ ) and expressed as picograms/milliliter/day.

\subsection{Cytomorphology of PCL/ Cell Matrices}

Cell morphology and viability were quantified using special stains [LIVE/DEAD ${ }^{\circledR}$ Viability Kit, Molecular Probes Inc. OR] and confocal microscopy [Leica DM1RE2, Leica Microsystems Inc., Bannockburn, IL]. Cell morphology was scored after staining the cytoskeleton (actin) with phallotoxin (Alexa Fluoro 647 Phalloidin, Molecular Cell Probes Inc. Oregon) and the nucleus with DAPI (Molecular Probes Inc. OR). Three representative fields were scored 0-4 with 0 representing the most healthy adherent cell and 4 representing the most pyknotic and crenated cell.

\subsection{Cellular Content}

Cellular content was determined by analyzing DNA content of PCL/ cell matrices using a modification of the previously described Hoechst 33258 Fluorometeric assay. Discs of PCL/ matrices containing chondrocytes cultured for 7 or 14 days were placed into a $2.0 \mathrm{ml}$ Eppendorf tube with $1 \mathrm{ml}$ of papain (Acros Organics) dissolved at $125 \mu \mathrm{g} / \mathrm{ml}$ in sterile $1 \mathrm{X}$ PBS pH 6.0, with $5 \mathrm{mM}$ cysteine $\mathrm{HCl}$ and $5 \mathrm{mM} \mathrm{Na}^{2}$ EDTA and incubated for $24 \mathrm{~h}$ at $60^{\circ} \mathrm{C}$. Papain digested samples were centrifuged at $1500 \mathrm{rpm}$ ( $0.2 \mathrm{rcf})$ for 30 seconds to pellet debris and the supernatant isolated. DNA standards of double stranded calf thymus DNA (Sigma) dissolved in TN buffer ( $50 \mathrm{mM}$ Tris $\mathrm{pH}$ 7.5, $150 \mathrm{mM} \mathrm{NaCl}$ ) and serially diluted ranged from $10 \mu \mathrm{g} / \mathrm{ml}$ to $500 \mu \mathrm{g} / \mathrm{ml}$. in a $\operatorname{Costar}^{\circledR} 96$ well, black, clear bottom assay plate (Corning, Inc.) $50 \mu$ l of papain digested sample or standard was placed in $200 \mu$ l of Hoechst 33258 dye (AnaSpec, Inc) diluted to $0.2 \mu \mathrm{g} / \mathrm{ml}$ in TN buffer. The plates were read on a UV/Vis spectrometer (Lambda 45, Perkin Elmer) at an excitation of $360 \mathrm{~nm}$, and emission of $460 \mathrm{~nm}$, with a $430 \mathrm{~nm}$ cutoff filter. DNA concentrations of samples were determined 
from the calf thymus DNA standard curve and reported in $\mu \mathrm{g} / \mathrm{ml}$.

\subsection{Proteoglycan Production in PCL/ Cell Matrices}

Extracellular production of proteoglycan was determined using a dimethylmethylene blue assay (DMMB assay) on papain digested supernatant from samples. DMMB reagent was prepared by adding $16 \mathrm{mg} 1,9$ dimethylmethylene blue (Polysciences, Inc) to $5 \mathrm{ml}$ ethanol followed by the addition of $2 \mathrm{ml}$ of formic acid and $2 \mathrm{~g}$ sodium formate. The volume was then brought to $1000 \mathrm{ml}$ with distilled water. Chondroitin Sulfate A from bovine trachea (Calbiochem) was serially diluted to create standards between $5 \mathrm{ng} / \mathrm{ml}$ and $50 \mathrm{ng} / \mathrm{ml}$. the assay was performed by combining $50 \mu \mathrm{l}$ of standard solution or sample solution with $200 \mu \mathrm{l}$ of the DMMB staining reagent and immediately determining the absorbance at $550 \mathrm{~nm}$ with a BioMate 3 Spectrophotometer (Thermo Electron Corporation). Proteoglycan concentrations were determined from the Chondroitin Sulfate standard curve and reported in $\mathrm{ng} / \mathrm{ml}$.

\subsection{Chondrocyte Gene Expression}

Discs of PCL/ Chondrocyte matrices were collected at day 7 and 14 of culture and placed into a $2.0 \mathrm{ml}$ Eppendorf tube with $1 \mathrm{ml}$ of a commercially available reagent composed of a monophasic solution of phenol and guanidine isothiocyanate (Trizol ${ }^{\circledR}$ reagent, GibcoBRL, Life Technologies, Frederick, MD). The PCL completely dissolved in the Trizol ${ }^{\circledR}$ reagent and total mRNA extracted with guanidine thiocyanate/phenol/chloroform and stored at $-80^{\circ} \mathrm{C}$ for real time reverse transcription polymerase chain reaction (RT-PCR) analysis. Equine specific primers and probes were designed and used (Primer Express software, Applied Biosystems Inc., Foster City, CA) to amplify and detect equine aggrecan, equine collagen type Ia, and equine collagen type II mRNA (Table 1). Relative gene expression was quantified by RT-PCR using 18s ribosomal RNA for normalization (Taqman 7000 sequence Detection System, Applied Biosystems Inc.). All Taqman probes were labeled at the 5' end with 6-carboxy-fluorescene (FAM) and at the 3' end with a minor groove binder non-fluorescent quencher. The thermal cycle protocol was $50^{\circ} \mathrm{C}$ for 2 in, $60^{\circ} \mathrm{C}$ for 30 min, $95^{\circ} \mathrm{C}$ for $5 \mathrm{~min}$, followed by 40 cycles of $95^{\circ} \mathrm{C}$ for $15 \mathrm{~s}$ and $60^{\circ} \mathrm{C}$ for $1 \mathrm{~min}$.

\subsection{Statistical Analysis}

Quantitative data (aggrecan [ddCT], collagen I [ddCT], collagen II [ddCT], proteoglycan $[\mathrm{ng} / \mathrm{ml}]$, \% chondrocyte viability, BMP-2 concentration $[\mathrm{pg} / \mathrm{ml}]$ ) were analyzed for difference among the three groups across days using a repeated two-factor analysis of variance with statistical significance set at $\mathrm{P}<0.05$. Scored data (morphology) was analyzed among groups with a KruskalWallis Rank test $(\mathrm{P}<0.05)$.

\section{RESULTS}

\subsection{Confirmation of Gene Transduction: GFP}

Transduction efficiency (GFP positive cells) was $>80 \%$ and only detected in Ad-GFP transduced chondrocytes. GFP expression intensity was high and sustained for the 14 days of the study (Figure 1).

Table 1. Equus caballus primer and probe sequences for RT-PCR analysis of gene sequences.

\begin{tabular}{|c|c|c|}
\hline \multirow{4}{*}{ Type II collagen } & Forward Primer & $\begin{array}{l}\text { 5'-AAGAGCGGAGACT } \\
\text { GGATTGAC-3' }\end{array}$ \\
\hline & Reverse Primer & 5'-TCCATGTTGCAGA \\
\hline & & 5'-AACCAGGGCTGCA \\
\hline & Probe & CCTTAGACGCC-3' \\
\hline \multirow{3}{*}{ Type I collagen } & Forward Primer & $\begin{array}{l}\text { 5'-CTGTCATTTCTCTA } \\
\text { CTGGCGAAAC-3' }\end{array}$ \\
\hline & Reverse Primer & $\begin{array}{l}\text { 5'-CCAGTTCTTGGCTG } \\
\text { GGATGT-3' }\end{array}$ \\
\hline & Probe & $\begin{array}{l}\text { 5'-TGCATTCGGGCTCA } \\
\text { ACCTGAA-3' }\end{array}$ \\
\hline \multirow{3}{*}{ Aggrecan } & Forward Primer & $\begin{array}{l}\text { 5'-CCGCTGGTCAGATG } \\
\text { GACACACT-3' }\end{array}$ \\
\hline & Reverse Primer & $\begin{array}{l}\text { 5'-GAAGAAGTTGTCG } \\
\text { GGCTGGTT-3' }\end{array}$ \\
\hline & Probe & $\begin{array}{l}\text { 5'-CTTGCAATTTGAGA } \\
\text { ACTGGCGCCC-3' }\end{array}$ \\
\hline
\end{tabular}

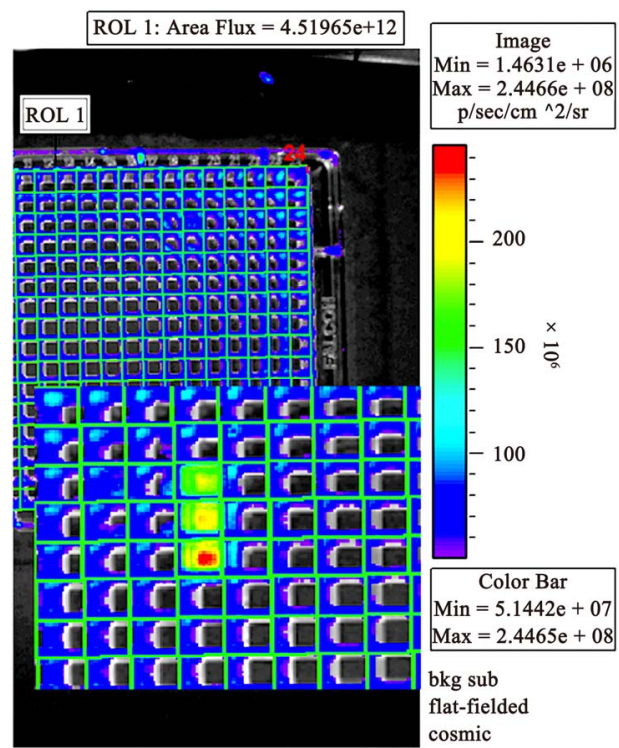

Figure 1. IVIS analysis of positive GFP fluorescence in Ad-GFP transduced chondrocytes (central 3 wells). Adjacent wells contained untransduced cells and Ad-BMP-2 transduced cells which had no GFP expression. 


\subsection{Transgene Protein Expression}

Gene transduction and protein expression were confirmed for the Ad-BMP-2-transduced chondrocytes in the PCL matrices on days 7 and 14 of culture. BMP concentration was $>150,000 \mathrm{pg} / \mathrm{ml}$ in Ad-BMP-2-transduced $\mathrm{PCL} /$ cell matrices and $<100 \mathrm{pg} / \mathrm{ml}$ in untreated and AdGFP PCL/ cell matrices.

\subsection{Scanning Electron Microscopy}

Scanning electron microscopy of PCL scaffolds demonstrated a random woven pattern of fibers in the 300-1000 $\mathrm{nm}$ range with an average pore size of $\sim 30 \mathrm{~nm}$ (Figure 2). Toluidine blue stained frozen cross sections of the $\mathrm{PCL} /$ cell scaffolds demonstrated penetration to $3 / 4$ depth by $5 \times 105$ and $1 \times 106$ cells/ scaffold in a 30\% serum gradient by day 7 (Figures 3A-B). Cell seeding density of $1 \times 105$ cells, $10 \%$ serum gradient and 2 days were insufficient to produce chondrocyte penetration of PCL matrices. Confocal microscopy of stained untreated chondrocytes and GFP expressing chondrocytes seeded on PCL matrices demonstrated an even distribution of cells with normal morphology, sustained gene expression, and cell viability in situ for 14 days (Figures 4A-B).

\subsection{Cytomorphology of PCL/ Cell Matrices}

Cell morphology score (median 4; range 3-4) and nuclear morphology score (median 3; range 3-4) was not different $(\mathrm{P}>0.05)$ among untreated, Ad-GFP, and AdBMP-2 PCL/ cell matrices at both days 7 and 14 .

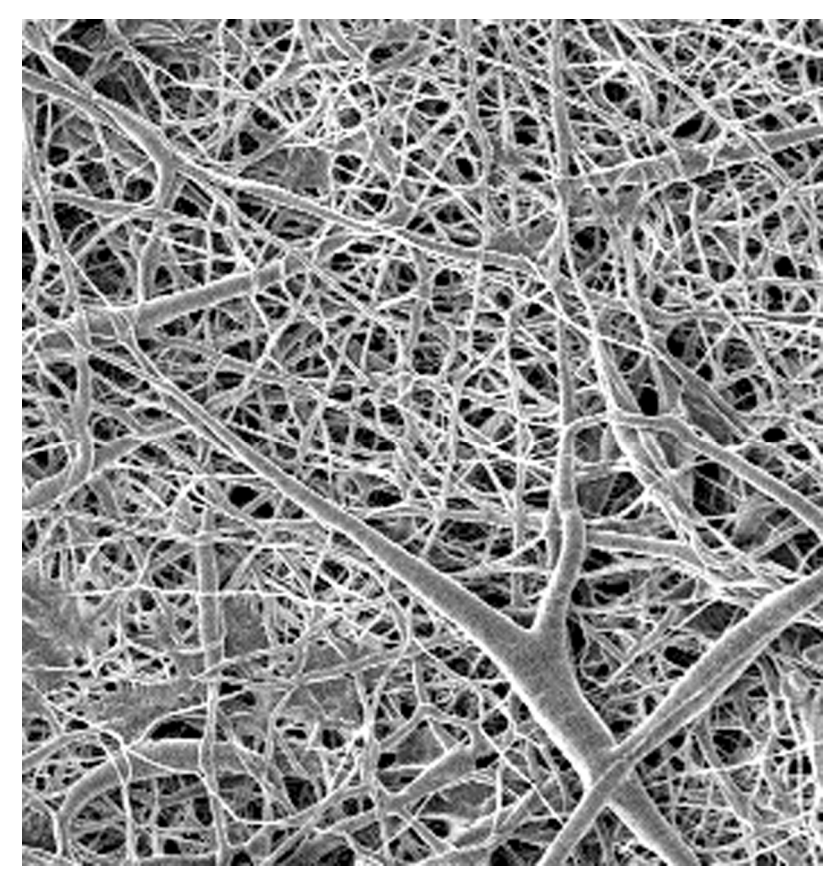

Figure 2. Scanning electron microscopy of the scaffold surface (1000X).

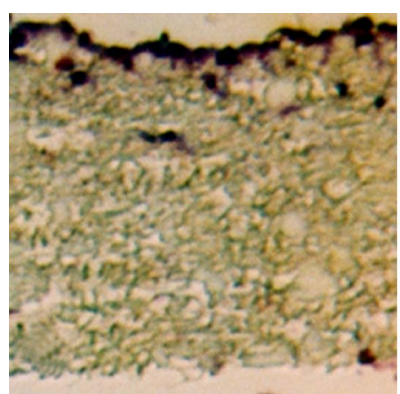

(a)

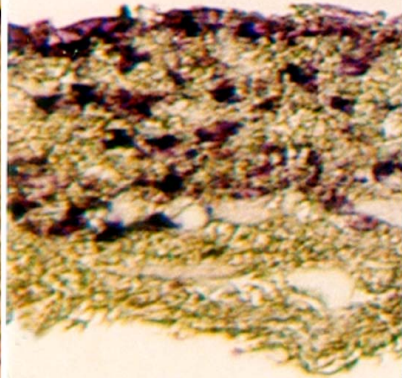

(b)
Figure 3. Toluidine blue positive chondrocytes (a) on the surface of the PCL at day 2. Toluidine blue positive chondrocytes (b) penetrating most of the scaffold with a $20 \%$ FBS gradient and $1 \times 106$ cell seeding density.

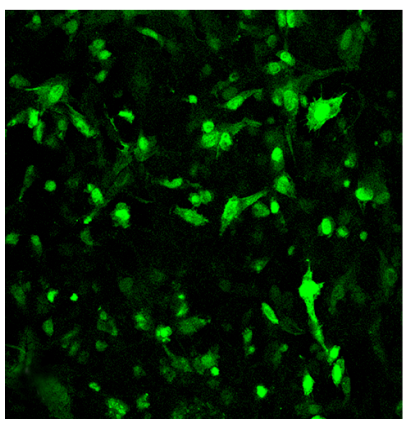

(a)

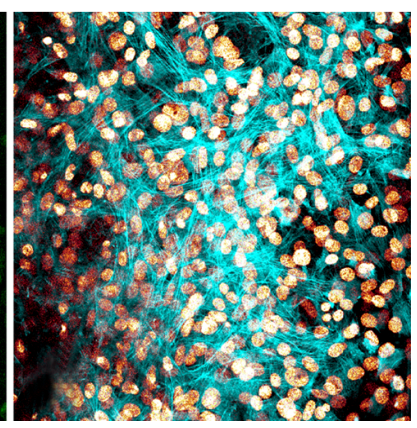

(b)
Figure 4. Cells transduced with Ad-GFP and suspended in scaffold demonstrated fluorescence under confocal microscopy (a) and had similar cell numbers and morphology to other transduced and untransduced cells at day 7 (b).

\subsection{Cell Content}

DNA content $(\mu \mathrm{g} / \mathrm{ml})$ was not different among untreated, Ad-GFP, and Ad-BMP-2 PCL/ cell matrices at day 7, but was significantly decreased in Ad-GFP and increased in Ad-BMP-2 by day $14(\mathrm{P}<0.01)$ (Figure 5A).

\subsection{Proteoglycan Production in PCL/ Cell Matrices}

Proteoglycan content (ng/ml) within the PCL/ cell matrices was significantly greater in the Ad-BMP-2 treated matrices by day 7 and continued to significantly increase only in the Ad-BMP-2 matrices ( $\mathrm{P}<0.05$ ) (Figure 5B).

\subsection{Chondrocyte Gene Expression}

Quantitative gene expression was expressed as the inverse of Delta CT values so that positive values correlated to increased gene expression. Ad-BMP-2 matrices has significantly greater Type II collagen $(\mathrm{P}<0.002)$ and aggrecan $(\mathrm{P}<0.001)$ gene expression than untreated and Ad-GFP matrices by day 7 and sustained until at least day 14 . There was no difference in type I collagen gene expression among groups (Figures 6A-C). 


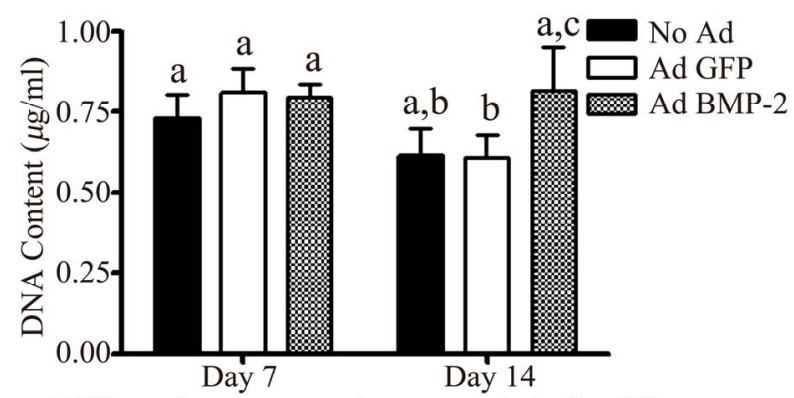

Different letter superscripts are statistically different $(\mathrm{p}<0.01)$

(a)

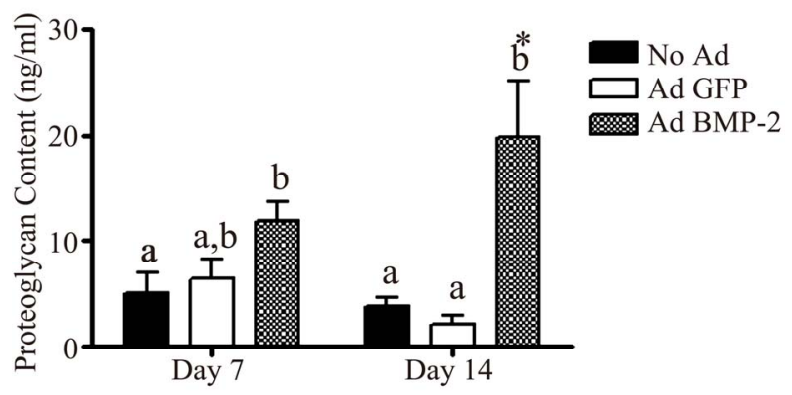

Different letter superscripts are statistically different $(p<0.05)$

*indicates a statistically significant increase compared to Day $7(\mathrm{p}<0.03)$

(b)

Figure 5. DNA content (a) decreased on day 14 as compared to day 7 except in the Ad-BMP2 treated group ( $\mathrm{p}<$ 0.01 ) which sustained their cell numbers. Cells transduced with Ad-BMP2 (b) had significantly greater proteoglycan content by day $7(\mathrm{p}<0.05)$, which had further increased by day $14(\mathrm{p}<0.03)$.

\section{Collagen Type II Expression}

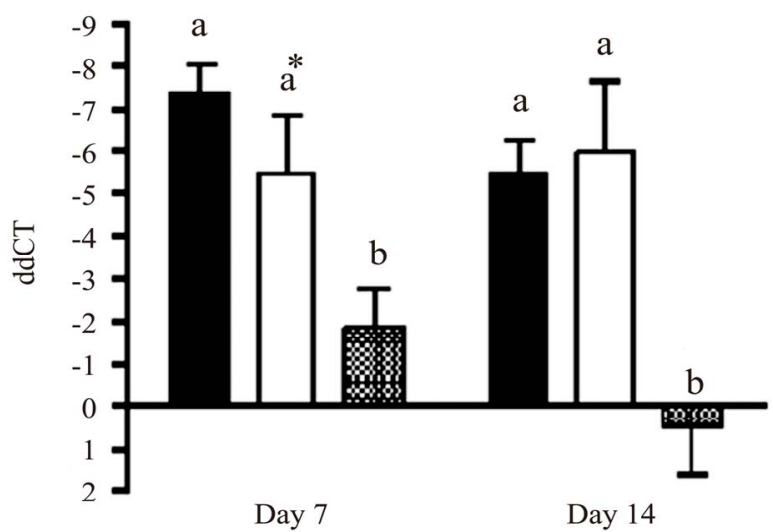

Different letter superscripts are statistically different $(\mathrm{p}<0.004)$ *indicates a trend toward significance compared to AdBMP-2 vs No Ad group $(\mathrm{p}=0.10)$

(a)
Aggrecan Expression

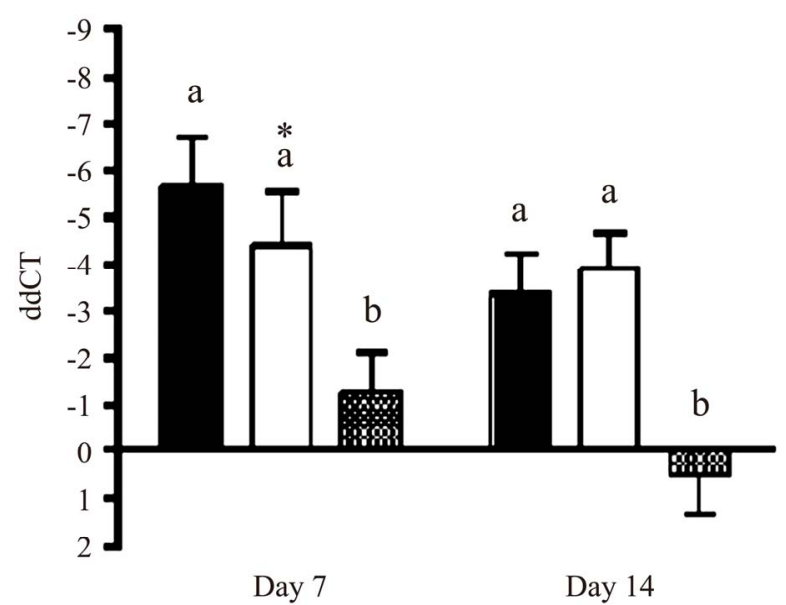

Different letter superscripts are

statistically different $(\mathrm{p}<0.004)$

*indicates a trend toward significance compared to Ad BMP-2 vs No Ad group $(\mathrm{p}=0.11)$

(b)

Collagen Type I Expression

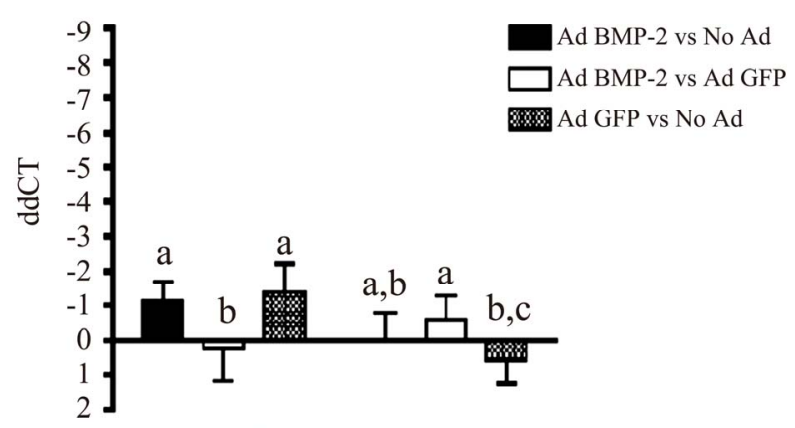

$$
\text { Day } 7 \quad \text { Day } 14
$$

Different letter superscripts are statistically different $(\mathrm{p}<0.04)$

(c)

Figure 6. Cells transduced with Ad-BMP2 had significantly greater gene expression of chondrogenic markers including Type II collagen (a) and aggrecan (b) and significantly less gene expression of Type I collagen (c).

\section{DISCUSSION}

Our data demonstrated that a serum gradient can be used to attract chondrocytes to seed into an electrospun PCL nanofiber scaffold and sustain chondrogenic phenotype in standard media. Nanofiber scaffolds offer the advantage of smaller biologic fiber diameters, but this woven mesh can be a challenge for cells to permeate the scaffold. Our work demonstrated this as the chondrocytes remain- 
ed on the surface in the control specimens. This is particularly challenging for relatively nonmobile chondrocytes that must dedifferentiate to a fibroblastic phenotype to migrate along fibrils and into pores. In our study, BMP2 sustained chondrogenic phenotype and extracellular matrix production while permitting these cells to enter the scaffold. For cartilage engineering, migration is particularly relevant to accommodate the thickness of a scaffold desired for cartilage regeneration (100-300 uM). Although it is possible to incorporate cells into a scaffold using an in situ cell seeding protocol [38], or by modifying the electrospinning protocol to produce larger fibers (in the micrometer range with larger pore sizes of $>100 \mathrm{uM}$ $[23,29])$, these methods are potentially handicapped by injury or contamination of cells or loss of the bioactivity advantage of the nanofibrous scale. In vivo generation of a serum gradient in the base of a cartilage defect is potentially achievable with the use of autologous serum products placed in the bed of debrided cartilage defects.[40] Commercially available platelet rich plasma or plasma concentrate products have been shown to have increased growth factor concentration of TGFbeta1 and 2 as well as other growth factors that may serve as a chemoattractant to chondrocytes layered on the surface of a scaffold in vivo. [41] Studies to further investigate this are warranted. These biologic plasma/fibrin products offer the additional advantage of serving as a biologic glue that may be able to help secure the scaffold into the defect. Fibrin glue is reported to secure cells within full-thickness cartilage defects in animal models [42].

In our study, the chondrocytes engineered to express BMP-2 had accelerated and amplified chondrogenesis within the scaffold as compared to control cells. In a previous in vitro study, chondrocytes incorporated in a hydrogel had enhanced matrix generation when the media was supplemented with TGFbeta3, a known chondrogenic growth factor. [11] Supplementing cells within a scaffold with a growth factor solution is technically difficult in vivo, other than by using a serum/plasma product as described above. Saturation of the scaffold with a TGFbeta solution is likely to have the TGFbeta rapidly leave the site or be diluted by joint fluid. Engineering of chondrocytes with chondrogenic genes offers an alternative for sustained trophic influences on the cells within the scaffold as demonstrated with BMP2 in our study. Additionally the release of soluable BMP2 will have a paracrine effect on other cells migrating into the site to heal the defect such as bone marrow-derived cells or synovial fibroblasts. Other genes such as insulin-like growth factor or TGFbeta may function similarly and could be used in chondrocyte engineering. The process of chondrocyte transduction with adenovirus did not nullify this trophic effect in our study. Methods of cell transdu- ction other than use of adenovirus may offer advantages, most notably a more sustained gene expression [43]. Our data provided evidence that engineering cells can provide enhanced chondrogenesis in Electrospun PCL nanofiber scaffolds for use in cartilage tissue engineering.

Current techniques under investigation for autologous chondrocyte transplantation include direct intraoperative processing of autologous articular cartilage to expose or isolate chondrocytes for immediate reimplantation [25] or chondrocyte expansion in culture prior to reimplantation at a second surgery. Gene transduction with BMP-2 can occur in under 2 hours and could be a practical genetic engineering technique to augment autologous cells with genes promoting chondrogenesis in the operating room. Other techniques that focus on autologous chondrocyte expansion prior to reimplantation at a second surgery would also be readily amenable to genetic engineering as described in this report. This study provides evidence that this process holds merit for potential clinical application. Our study was limited to in vitro processing and further studies to confirm this potential in an in vivo animal model are warranted.

\section{REFERENCES}

[1] Simon, T.M. and Jackson, D.W. (2006) Articular cartilage: Injury pathways and treatment options. Sports Medicine and Arthroscopy Review, 14(3), 146-154.

[2] Chung, C. and Burdick, J.A. (2008) Engineering cartilage tissue. Advanced Drug Delivery Reviews, 60(2), 243-262.

[3] Kino-Oka, M., Maeda, Y., Yamamoto, T., Sugawara, K. and Taya, M. (2005) A kinetic modeling of chondrocyte culture for manufacture of tissue-engineered cartilage. Journal of Bioscience and Bioengineering, 99(3), 197-207.

[4] Thorvaldsson, A., Stenhamre, H., Gatenholm, P. and Walkenstrom, P. (2008) Electrospinning of highly porous scaffolds for cartilage regeneration. Biomacromolecules, 9(3), 1044-1049.

[5] Li, W.J. and Tuan, R.S. (2009) Fabrication and application of nanofibrous scaffolds in tissue engineering. Current Protocols in Cell Biology, Chapter 25(25), Unit 25 22.

[6] Jeong, C.G. and Hollister, S.J. (2010) A comparison of the influence of material on in vitro cartilage tissue engineering with PCL, PGS and POC 3D scaffold architecture seeded with chondrocytes. Biomaterials, 31(15), 4304-4312.

[7] Martinez-Diaz, S., Garcia-Giralt, N., Lebourg, M., et al. (2010) In vivo evaluation of 3-dimensional polycaprolactone scaffolds for cartilage repair in rabbits. American Journal of Sports Medicine, 38(3), 509-519.

[8] He, L., Liu, B., Xipeng, G., et al. (2009) Microstructure and properties of nano-fibrous PCL-b-PLLA scaffolds for cartilage tissue engineering. European Cells and Materials, 18, 63-74.

[9] Martins, A., Pinho, E.D., Faria, S., et al. (2009) Surface 
modification of electrospun polycaprolactone nanofiber meshes by plasma treatment to enhance biological performance. Small, 5(10), 1195-1206.

[10] da Silva, M.A., Crawford, A., Mundy, J., et al. (2009) Evaluation of extracellular matrix formation in polycaprolactone and starch-compounded polycaprolactone nanofiber meshes when seeded with bovine articular chondrocytes. Tissue Engineering Part A, 15(2), 377-385.

[11] Maher, S.A., Mauck, R.L., Rackwitz, L. and Tuan, R.S. (2010) A nanofibrous cell-seeded hydrogel promotes integration in a cartilage gap model. Journal of Tissue Engineering and Regenerative Medicine, 4(1), 25-29.

[12] Li, W.J., Danielson, K.G., Alexander, P.G. and Tuan, R.S. (2003) Biological response of chondrocytes cultured in three-di- mensional nanofibrous poly (epsilon-caprolactone) scaffolds. Journal of Medical Materials Research, 67(4), 1105-1114.

[13] Lee, J.J., Yu, H.S., Hong, S.J., Jeong, I., Jang, J.H. and Kim, H.W. (2009) Nanofibrous membrane of collagen-polycaprola- ctone for cell growth and tissue regeneration. Journal of Materials Science: Materials in Medicine, 20(9), 1927- 1935.

[14] Mierisch, C.M., Wilson, H.A., Turner, M.A., et al. (2003) Chondrocyte transplantation into articular cartilage defects with use of calcium alginate: the fate of the cells. Journal of Bone and Joint Surgery, 85A(9), 1757-1767.

[15] Ito, Y., Fitzsimmons, J.S., Sanyal, A., Mello, M.A., Mukherjee, N. and O'Driscoll, S.W. (2001) Localization of chondrocyte precursors in periosteum. Osteoarthritis and Cartilage, 9(3), 215-223.

[16] Li, J., Chen, Y., Mak, A.F., Tuan, R.S., Li, L. and Li, Y. (2009) A one-step method to fabricate PLLA scaffolds with deposition of bioactive hydroxyapatite and collagen using ice- based microporogens. Acta Biomaterialia, 6(6), 2013-2019.

[17] Mendes, S.C., Bezemer, J., Claase, M.B., et al. (2003) Ev aluation of two biodegradable polymeric systems as substrates for bone tissue engineering. Tissue Engineering, 9 (Suppl 1), 91-101.

[18] Duling, R.R., Dupaix, R.B., Katsube, N. and Lannutti, J. (2008) Mechanical characterization of electrospun polycaprolac- tone (PCL): A potential scaffold for tissue engineering. Journal of Biomechanical Engineering, 130(1), 011006.

[19] Gaumer, J., Prasad, A., Lee, D. and Lannutti, J. (2009) Structure-function relationships and source-to-ground distance in electrospun polycaprolactone. Acta Biomaterialia, 5(5), 1552-1561.

[20] Johnson, J., Niehaus, A., Nichols, S., et al. (2009) Electrospun PCL in vitro: a microstructural basis for mechanical property changes. Journal of Biomaterials Sicence, Polymer Edition, 20(4), 467-481.

[21] Li, W.J., Chiang, H., Kuo, T.F., Lee, H.S., Jiang, C.C. and Tuan, R.S. (2009) Evaluation of articular cartilage repair using biodegradable nanofibrous scaffolds in a swine model: A pilot study. Journal of Tissue Engineering and Regenerative Medicine, 3(1), 1-10.

[22] Fecek, C., Yao, D., Kacorri, A., et al. (2008) Chondrogenic derivatives of embryonic stem cells seeded into 3D poly- caprolactone scaffolds generated cartilage tissue in vivo. Tissue Engineering Part A, 14(8), 1403-1413.

[23] Nam, J., Rath, B., Knobloch, T.J., Lannutti, J.J. and
Agarwal, S. (2009) Novel electrospun scaffolds for the molecular analysis of chondrocytes under dynamic compression. Tissue Engineering Part A, 15(3), 513-523.

[24] Chang, K.Y., Cheng, L.W., Ho, G.H., Huang, Y.P. and Lee, Y.D. (2009) Fabrication and characterization of poly (gamma- glutamic acid)-graft-chondroitin sulfate/ polycaprolacto- ne porous scaffolds for cartilage tissue engineering. Acta Biomaterialia, 5(6), 1937-1947.

[25] Frisbie, D.D., Lu, Y., Kawcak, C.E., DiCarlo, E.F., Binette, F. and McIlwraith, C.W. (2009) In vivo evaluation of autologous cartilage fragment-loaded scaffolds implanted into equine articular defects and compared with autologous chondrocyte implantation. American Journal of Sports Medicine, 37 (Suppl 1), 71-80.

[26] Kang, X., Xie, Y., Powell, H.M., et al. (2007) Adipogenesis of murine embryonic stem cells in a three-dimensional culture system using electrospun polymer scaffolds. Biomaterials, 28(3), 450-458.

[27] Johnson, J., Nowicki, M.O., Lee, C.H., et al. (2009) Quantitative analysis of complex glioma cell migration on electrospun polycaprolactone using time-lapse microscopy. Tissue Engineering Part C, 15(4), 531-540.

[28] Drilling, S., Gaumer, J. and Lannutti, J. (2009) Fabrication of burst pressure competent vascular grafts via electrospinning: Effects of microstructure. Journal of Biomedical Materials Research Part A, 88(4), 923-934.

[29] Xian, C.J. and Foster, B.K. (2006) Repair of injured articular and growth plate cartilage using mesenchymal stem cells and chondrogenic gene therapy. Current Stem Cell Research \& Therapy, 1(2), 213-229.

[30] Puetzer, J.L., Petitte, J. and Loboa, E. (2010) Comparative review of growth factors for induction of 3-Dimensional in vitro chondrogenesis in human mesenchymal stem cells isolated from bone marrow and adipose tissue. Tissue Engineering Part B, 16(4), 435-444

[31] Zachos, T., Diggs, A., Weisbrode, S., Bartlett, J. and Bertone, A. (2007) Mesenchymal stem cell-mediated gene delivery of bone morphogenetic protein-2 in an articular fracture model. Molecular Therapy, 15(8), 1543-1550.

[32] van der Kraan, P.M., Davidson, E.N. and van den Berg, W.B. (2010) Bone morphogenetic proteins and articular cartilage to serve and protect or a wolf in sheep clothing's? Osteoarthritis and Cartilage, 18(6), 735-741.

[33] Kaps, C., Bramlage, C., Smolian, H., et al. (2002) Bone morphogenetic proteins promote cartilage differentiation and protect engineered artificial cartilage from fibroblast invasion and destruction. Arthritis \& Rheumatism, 46(1), 149-162.

[34] Majumdar, M.K., Wang, E. and Morris, E.A.. (2001) BMP-2 and BMP-9 promotes chondrogenic differentiation of human multipotential mesenchymal cells and overcomes the inhibitory effect of IL-1. Journal of Cell Physiology, 189(3), 275-284.

[35] Glansbeek, H.L., van Beuningen, H.M., Vitters, E.L., Morris, E.A., van der Kraan, P.M., and van den Berg, W.B. (1997) Bone morphogenetic protein 2 stimulates articular cartilage proteoglycan synthesis in vivo but does not counteract interleukin-1alpha effects on proteoglycan synthesis and content. Arthritis \& Rheumatism, 40(6), 1020-1028.

[36] Smith, P., Shuler, F.D., Georgescu, H.I., et al. (2000) Genetic enhancement of matrix synthesis by articular 
chondrocytes: Comparison of different growth factor genes in the presence and absence of interleukin-1. Arthritis \& Rheumatism, 43(5), 1156-1164.

[37] Zachos, T.A., Shields, K.M. and Bertone, A.L. (2006) Gene-mediated osteogenic differentiation of stem cells by bone morphogenetic proteins-2 or -6. Journal of Orthopaedic Research, 24(6), 1279-1291.

[38] Stankus, J.J., Guan, J., Fujimoto, K. and Wagner, W.R. (2006) Microintegrating smooth muscle cells into a biodegradable, elastomeric fiber matrix. Biomaterials, 27(5), 735-744.

[39] Nam, J., Huang, Y., Agarwal, S. and Lannutti, J. (2008) Materials selection and residual solvent retention in biodegradable electrospun fibers. Journal of Applied Polymer Science, 107(3), 1547-1554.

[40] Lopez-Vidriero, E., Goulding, K.A., Simon, D.A., Sanchez, M. and Johnson, D.H. (2010) The use of platelet-rich plasma in arthroscopy and sports medicine: Optimizing the healing environment. Arthroscopy, 26(2), 269-278.
[41] Sutter, W.W., Kaneps, A.J. and Bertone, A.L. (2004) Comparison of hematologic values and transforming growth factor- beta and insulin-like growth factor concentrations in platelet concentrates obtained by use of buffy coat and apheresis methods from equine blood. American Journal of Veterinary Research, 65(7), 924-930.

[42] Wilke, M.M., Nydam, D.V. and Nixon, A.J. (2007) Enhanced early chondrogenesis in articular defects following arthroscopic mesenchymal stem cell implantation in an equine model. Journal of Orthopaedic Research, 25(7), 913-925

[43] Santangelo, K.S., Baker, S.A., Nuovo, G., Dyce, J., Bartlett, J.S. and Bertone, A.L. (2007) Detectable reporter gene expression following transduction of adenovirus and adeno-associated virus serotype 2 vectors within full-thickness osteoarthritic and unaffected canine cartilage in vitro and unaffected guinea pig cartilage in vivo. Journal of Orthopaedic Research, 28(2), 149-155. 